\title{
Educação instrumental e formação cidadã: observações críticas sobre a pertinência social da universidade
}

\section{Instrumental civic education and critical training: remarks on the university of social relevance}

\author{
Pedro Goergen ${ }^{1}$
}

\begin{abstract}
RESUMO
O ensaio examina a relação entre universidade e sociedade desde a perspectiva dos conceitos de educação instrumental e educação cidadã. Argumenta que a pertinência social da universidade deve responder ao critério de justiça social e democracia que suas contribuições visam incrementar. Restrito ao aspecto do ensino, sob o recorte conceitual da educação instrumental e educação cidadã, o texto sugere que não cabe à universidade promover uma educação instrumental focada apenas na adaptação dos estudantes à realidade socioeconômica, mas também, formar cidadãos autônomos, críticos e reflexivos, socialmente competentes.

Palavras-chave: Universidade; pertinência social; educação instrumental; formação cidadã; subjetividade.
\end{abstract}

\begin{abstract}
The paper examines the relationship between university and society from an approach based on instrumental education and civic education. It is argued that the university's social pertinence must address the criteria that its contributions seek to foster, such as social justice and democracy. Restricted to the aspect of teaching, under the conceptual framework of instrumental education and citizen education, the text suggests that it is
\end{abstract}

1 Professor Titular da Universidade de Sorocaba (Uniso), Brasil, e Professor Titular aposentado/colaborador da Universidade de Campinas, Brasil. 
not up to the university to promote an instrumental education focused on student's adaptation to the social and economic reality, but to shape autonomous, critical and reflexive citizens who are socially competent. Keywords: university; social pertinence; instrumental education; citizen education; subjectivity.

\section{Introdução}

Os termos "educação instrumental”, "formação cidadã” e "pertinência social” que compõem o título acima, certamente representam temas centrais da teoria educacional contemporânea. No entanto, ao contrário do que muitas vezes se supõe, não se trata de conceitos homogêneos e de sentido consensual. Educação instrumental, por exemplo, pode assumir tanto um sentido predominantemente negativo na acepção dos críticos, quanto positivo para os defensores do modelo social e educacional vigentes. Do mesmo modo, formação cidadã em certos contextos é entendida como educação favorável à integração social e noutros como educação para a autonomia e distanciamento entre indivíduo e sociedade. Finalmente, pertinência social ora designa uma submissão acomodativa da universidade às exigências do mercado, ora a contribuição crítico-construtiva da universidade para a construção de uma sociedade melhor.

No presente ensaio, pretendo primeiro, lançar um olhar crítico sobre o conceito de pertinência social da universidade na tentativa de desvelar eventuais supostos ideológicos nele envolvidos quando entendido como adaptação da universidade ao socioeconômico. Num passo seguinte, me proponho discutir brevemente o conceito de educação instrumental como um dos aspectos centrais da pertinência social da universidade. Por último, tento interpretar a ideia de formação cidadã na perspectiva da formação do sujeito como um elemento indispensável ao sentido mais amplo e transformador da pertinência social.

No conjunto, desejo contribuir para um aprofundamento crítico do conceito de pertinência social através do resgate da formação crítica dos estudantes enquanto pessoas e cidadãos capazes não só de se integrar na sociedade, mas também, de contribuir para a construção de uma sociedade mais justa, democrática e humana. 


\section{Pertinência social da universidade}

No seu livro Um novo paradigma - para compreender o mundo de hoje (2006) Alain Touraine defende a ideia de que estamos vivendo o "desaparecimento do universo que chamávamos de social”. Nossa vida social estaria sendo invadida, por um lado, "pelas forças não-sociais que são o interesse, a violência e o medo e, por outro, por atores cujos objetivos são a liberdade pessoal ou a pertença a uma comunidade herdada, objetivos que não são, nem sequer eles, propriamente sociais" (TOURAINE, 2006, p. 10). A tese da dissolução das sociedades como "sistemas integrados e portadores de um sentido geral" e da consequente necessidade de tomarmos como ponto de partida a "destruição de todas as categorias sociais" (TOURAINE, 2006, p.10), nos leva a perguntar qual seria, nesse caso, o ponto de referência do discurso da pertinência social da universidade na pesquisa e no ensino. Teria o nosso discurso acadêmico perdido toda chance de discernimento crítico, toda a independência com relação a uma realidade ideologicamente construída e pervagada por forças vazias de sentido social vinculante? Seria a sociedade circular, viciosa, destituída de qualquer rumo comparável a uma embarcação que navega ao sabor de ventos incontroláveis? Nos termos postos por Touraine, essas perguntas deveriam ser respondidas positivamente concluindo que ao homem não restam esperanças de tornar-se senhor da história como sempre pretendeu. Mesmo sem concordar com essa ideia, há que se levar em conta as intrigantes colocações do autor porquanto elas tem suporte na real precarização dos laços sociais, da fragmentação de valores e da dispersão de sentidos que hoje vivemos.

Buscando evitar o eventual pessimismo que suas conclusões poderiam sugerir, o sociólogo francês entende que as perdidas categorias sociais estariam sendo substituídas por novas categorias culturais capazes de nos livrar da angustiante sensação da perda total de sentido. Dessa forma, o fim do mundo social não seria o fim do mundo, mas apenas o mundo visto de outra forma. A nova tarefa seria agora "definir em que termos se constrói esse novo paradigma, cuja novidade se faz sentir em todos os aspectos da vida coletiva e pessoal” (TOURAINE, 2006, p. 12). Ao invés do "nós" social, o novo modelo cultural estaria centrado no sujeito e nos direitos culturais. Embora não seja possível no presente momento examinar em detalhe esta tese, pode-se reconhecer, de um lado, que é real a fragilização do paradigma social ante o apelo cada vez mais forte do individualismo e, de outro, aceitar a indicação da recuperação da subjetividade.

Os indivíduos, ao invés de se identificarem com valores e estratégias exteriores concentram-se mais e mais sobre si mesmos lutando pela liberdade 
contra a alienação que ameaça destruí-los. Trata-se, segundo Touraine, de uma nova forma de individualismo contrário ao individualismo alienado e manipulado pelos poderes do mercado. É o sujeito que se rebela contra as forças da religião, da política e da própria socialidade que ameaçam destruí-lo. Com isso concorda o culturalista indo-britânico Komi K. Bhabha ao dizer que "encontramo-nos no momento de trânsito em que espaço e tempo se cruzam para produzir figuras complexas de diferença e identidade, passado e presente, interior e exterior, inclusão e exclusão" (BHABHA, 2007, p. 20).

Sabe-se que essas ideias não encontram acolhida entre aqueles que representam a vertente de tradição socialista. Essas duas perspectivas que, grosso modo, norteiam a discussão atual sobre a relação entre indivíduo e sociedade, também nos servem de parâmetro para refletir sobre a pertinência social da universidade, uma vez que ela abriga, simultânea e paralelamente, a mesma dicotomia discursiva e prática. De um lado, perfila-se o discurso da individualidade, do conhecimento e das competências centrais ao mundo exigente e competitivo do mercado e, de outro, o discurso socializante da urgente recuperação de valores sociais e comunitários como condição de uma sociedade justa e democrática.

Na maioria das vezes, esses dois discursos seguem paralelos e surdos um ao outro, visando ora o bem individual, ora o bem social. O primeiro se conduz pelo padrão da utilidade e da eficiência tendo como parâmetro a razão estratégica ou instrumental enquanto o segundo se orienta pelo ideal altruísta do coletivo e do social articulado pela razão dialético-crítica. A razão instrumental responde à exigência sistêmica de performatividade e a razão crítica às expectativas de humanização coletiva. É no contexto dessa ambivalência discursiva e prática que pode e, a meu ver, deve ser colocada a questão da pertinência social da universidade, uma vez que é exatamente na correlação dessas duas perspectivas contingentes e contraditórias que se abre o espaço de uma relação pertinente e realista entre universidade e sociedade. Sugiro, portanto, a aproximação entre a perspectiva social e subjetiva à luz de uma nova e não instrumental proposta de formação do indivíduo. Na parte final do presente trabalho tentarei mostrar que, na verdade, essas perspectivas se pressupõem mutuamente na medida em que representam duas dimensões constituintes do ser humano.

Por ora atenho-me a uma breve análise do caráter ambíguo do conceito de pertinência social, hoje o grande mote dos críticos do suposto elitismo e distanciamento social da universidade. O uso superficial do termo "pertinência" pressupõe uma autonomia e neutralidade, na verdade, fictícias, do social como um conjunto de necessidades e aspirações pretensamente representantes das genuínas expectativas da sociedade. No entanto, à medida que se impõe a lógica dos interesses econômicos globais, destaca-se como reação a diversidade cultural, desafiando a fé incondicional na capacidade de autocriação e de auto- 
transformação das sociedades como garantia de coesão. Em especial no mundo globalizado de hoje, as sociedades têm seu rumo fortemente influenciado ou mesmo determinado por influências externas, sobretudo as de natureza econômica, mas também cultural.

Além dessas ambivalências e tensões resultantes da sobreposição de espaços globais e locais, as observações de Touraine e Bhabha apontam para outra dimensão das relações sociais determinadas não pelas narrativas territorial, política ou econômica, mas pela identidade cultural, religiosa ou étnica. As migrações físicas ou virtuais entre ricos e pobres, entre o passado e o futuro, o psíquico e o social, o idêntico e o diferente, desenvolvem no mundo globalizado uma "intimidade intersticial" e cultural (BHABHA, 2007) entre fronteiras que tornam as perspectivas de consensualidade ainda mais complexas e conflituosas do que no confronto entre os interesses locais e globais próprias da ordem econômica.

No modelo tradicional da sociedade anterior à globalização e à informação, a própria sociedade era a referência extrema e constante de seu desenvolvimento. Naquele contexto, a noção de sociedade podia representar o padrão de avaliação das formas de conduta pessoais ou coletivas no conjunto social. Em consequência, aceitava-se que

a escola devia transmitir conhecimentos, formar o espírito, impor disciplinas e fazer desaparecer as diferenças entre os indivíduos em nome da uniformidade da norma, ou seja, pela submissão de todos às formas de pensamento e de vida que asseguram o sucesso da produção e compensam os melhores (TOURAINE, 2006, p. 59).

Como integrantes de um imenso coletivo não importava aos indivíduos a sua autonomia, mas o lugar que ocupavam. Apagava-se, assim, a subjetividade individual submersa sob interesses gerais e dominantes da sociedade.

Em conjunto, os grandes fluxos econômicos e os interesses que se escondem por detrás deles, bem como as novas categorias de raça, gênero, geração, etnia e cultura reconfiguram e redeterminam não só as posições do sujeito, mas também, a relação das instituições com o todo social. Essas condições constituem as pretensões de identidade subjetiva e institucional no mundo contemporâneo. O que está em questão é o próprio conceito de comunidade humana que se encontra em radical processo de revisão. Para isso, contribuem tanto o processo de globalização discutido pelos economistas quanto o silencioso movimento intersticial dos entre-lugares culturais anunciado pelos culturalistas. 
Temos, de um lado, um cenário em que acontecimentos, conflitos, crises e urgências econômicas internacionais se projetam sobre os rumos tanto da economia quanto da ciência \& tecnologia regionais e, de outro, um cenário determinado por anseios, necessidades e aspirações das comunidades locais ou regionais. Alocadas nesse entre-lugar como podem as universidades atender ao mandado da pertinência social? Devem elas orientar-se nos grandes movimentos econômicos e científico-tecnológicos mundiais que via de regra representam interesses de países desenvolvidos e desprezar as necessidades e anseios locais ou, ao contrário, priorizar esses últimos relegar os primeiros? Ou seria possível conciliar as duas coisas?

Se a universidade abrir mão de sua tarefa crítica e simplesmente aceitar a realidade como fato, ela pode transformar-se ou num instrumento dos grandes movimentos internacionais e passar ao largo dos interesses regionais ou priorizar comunitários e distanciar-se da dimensão global e internacional. A tese da pertinência social da universidade precisa, portanto, ter em conta a nova racionalidade de funcionamento da sociedade globalizada e informatizada que envolve tanto a dimensão global, de recorte predominantemente econômico, quanto também a regional, de traço mais bem cultural.

No entanto, as fronteiras entre o global e o local ao mesmo tempo se afrontam e se unem, formando cenários multideterminados, mutantes e perpassados por interesses conflituosos, razão pela qual a universidade precisa submetê-los a um aprofundado exame crítico antes de vincular a eles suas atividades de pesquisa, ensino e extensão. A partir dessas considerações, pode-se entrever novas e inusitadas tarefas para a academia no que diz respeito à sua relação com a sociedade. Na verdade, a universidade que se ocupa afirmativamente da ciência $\&$ tecnologia ainda precisa desenvolver sensores para perceber e decifrar a emergente dimensão cultural para a qual nos chamam a atenção Touraine e Babha.

Nos primórdios da universidade moderna, Humboldt imaginou uma academia independente e autônoma, dedicada à busca da verdade e do conhecimento puros, na certeza de que renderiam frutos para o Estado e, de forma indireta, também para o futuro da sociedade e o bem-estar dos cidadãos. Como esse era um tema política e economicamente relevante para a sociedade alemã daquele tempo, foi certamente um projeto bem sucedido também do ponto de vista social. Nascia assim o modelo de universidade orientado apenas nos moldes daquilo que parecia adequado às exigências da razão e da verdade científica e distante das impurezas históricas da sociedade.

A reação a esse modelo chegou com os movimentos antiautoritários do início da segunda metade do século passado, acordando a universidade de sua altivez e letargia para a concretude das necessidades e exigências sociais. Surgia assim o mandado da pertinência social, ou seja, a expectativa de uma universi- 
dade que deveria orientar suas atividades nas necessidades e problemas sociais concretos. No entanto, contrariamente ao que haviam imaginado os mentores da renovação, a universidade deixou de ser, pelo menos em grande medida, o lugar do pensamento criativo capaz de disponibilizar o potencial da ciência \& tecnologia para solução dos problemas sociais, preferindo seguir os rumos indicados pelo modelo neoliberal, ou seja, pelo economicismo consumista e utilistarista. Como consequência, a pesquisa passou a investigar predominantemente questões direta ou indiretamente impostas pelo modelo político-econômico; o ensino a transmitir conhecimentos e habilidades relacionadas ao mercado de trabalho; e a extensão a buscar soluções emergenciais decorrentes da própria natureza do sistema.

Nesse contexto, pode-se distinguir duas orientações básicas na relação entre universidade e sociedade. Ora ela assume um papel crítico-transformador, ora age em função do sistema. No primeiro caso, orienta suas atividades de pesquisa, ensino e extensão para a transformação social na perspectiva de uma sociedade economicamente mais justa, politicamente mais democrática e ecologicamente mais sustentável. No segundo, dimensiona suas atividades de acordo com as expectativas da sociedade tal como ela existe. No primeiro sentido, a universidade assume posição crítica de distanciamento e superação do real e, no segundo, submete-se ao real buscando o aperfeiçoamento sistêmico sem considerar seu sentido humano.

Embora essas duas dimensões da pertinência social estejam presentes na universidade contemporânea, é facilmente perceptível e ademais comprovado por inúmeras análises que predomina a adaptação e acomodação não críticas da universidade ao modelo político-econômico dominante. Seja como for, importante para o nosso contexto é reter que a pertinência social não é um conceito neutro e per se positivo. Ele pode ter sentidos distintos e servir a interesses diferentes a depender da leitura que se tem da própria função da universidade no contexto social. Em resumo, é preciso considerar que a pertinência social não se reduz às dimensões do conhecer e da utilidade, mas se estende às dimensões da ética e do ser. Pertinência social é, por isso, um conceito chave, pois de sua interpretação e concretização resultam modelos diferentes de universidade. Esse fato poderia ser detalhado a partir de cada um dos principais ramos das atividades acadêmicas de pesquisa, extensão e ensino. No momento, desejo apenas chamar atenção para o aspecto do ensino e tentar mostrar como ali se aplica o conceito de educação instrumental. 


\section{O modelo da educação instrumental}

Embora profética, a expressão "razão instrumental”, formulada por Adorno e Horkheimer em 1947, ainda não podia antever as dimensões que o processo de submissão e objetalização do conhecimento humano haveria de assumir ao longo das décadas posteriores. Mais e mais aumentaram as pressões do real sobre o sujeito ameaçado de ser absorvido pela engrenagem econômica e de perder a autonomia sobre seus valores e aspirações. Até mesmo a linguagem, forma e expressão máxima da identidade, cedeu lugar ao imediatismo do consenso e da harmonia. Os impulsos de subordinação do sujeito em relação à realidade impostas de fora para dentro acabam sendo interiorizadas. Na linguagem de Adorno e Horkheimer, "o factual tem a última palavra, o conhecimento restringe-se à sua repetição, o pensamento transforma-se em mera tautologia” (ADORNO; HORKHEIMER, 1985, p. 39). Desse modo, a informação se sobrepõe ao pensamento que definha sob a pressão do real que tudo gerencia em nome da eficácia e da utilidade. Na mesma medida em que o mundo se pulveriza numa multiplicidade de fenômenos desconectados e sem coerência, a verdade perde sua transcendência e torna-se imagem espelhada da realidade. Esse processo não apenas se reflete sobre o processo educativo, mas se serve desse para a sua mais plena realização. Nesse sentido, pode-se falar de educação instrumental.

Envolvida por esse inexorável movimento pragmático que postula o real como paradigma absoluto da verdade e da ética, também a universidade assume uma noção de progresso linear, homogêneo e autônomo sem se preocupar com os elementos de regressão material e humana nela envolvidos. Apesar dos revezes sofridos por esse modelo de progresso baseado na confiança ilimitada na ciência \& tecnologia, a universidade segue insensível às ambivalências que a tudo perpassam. Os grandes temas que preocupam a humanidade encontram-se muitas vezes presentes nas cantinas e cafeterias, mas permanecem ausentes dos laboratórios, dos gabinetes de estudo e das salas de aula. Ali se cultiva o que Marcuse (1997) chamou de "cultura afirmativa" dominada pelo modelo do pensamento instrumental, ou seja, do pensamento posto a serviço da realidade. "Na cultura afirmativa", diz o filósofo, "a renúncia se vincula à decadência exterior do indivíduo, com seu enquadramento disciplinado na adequação numa ordem má” (MARCUSE, 1997, p. 130) que oculta sob o manto dos fatos o significado da verdade tal como se conhece na filosofia. E, segundo alertam Adorno e Horkheimer, “[...] se o esclarecimento não acolhe dentro de si a reflexão sobre esse elemento regressivo, ele está selando seu próprio destino [...] de pensamento cegamente pragmatizado [...] sem relação com a verdade” (ADORNO; HORKHEIMER, 1985, p. 13). 
À medida que definha a verdade, acelera-se o triunfo dos poderes econômicos que destroem os laços da socialidade próprios da ordem dos valores e sentidos humanos transcendentes à ordem real. Com a ruptura do laço social, fortalecem-se os projetos individuais de vida e, desse modo, o ensino e a pesquisa não têm mais como substrato a socialização e sim a individualização, o proveito e as vantagens pessoais num contexto em que a solidariedade é superada pela individualidade.

Nessas circunstâncias, delineiam-se três atitudes possíveis. Primeiro, a crítica e negação radical do modelo social que encarna a perversidade das forças econômicas que produzem um cenário de inaceitável injustiça social e destruição ambiental. Segundo, a postura reformista que alimenta a esperança de uma sociedade melhor a partir de melhorias e transformações do modelo atual. E, por último, a atitude resignativa que não vê outra alternativa senão lutar pela integração nos quadros beneficiados do sistema. A primeira vive da esperança na superação revolucionária do modelo atual e sua substituição por um novo, livre de diferenças e injustiças. A segunda e a terceira, cada uma à sua maneira, apostam suas fixas na educação ou alimentando esperanças num futuro melhor pela formação do sentido social das pessoas ou simplesmente buscando integrá-las no sistema, equipando-as com os recursos necessários para o sucesso individual. Nesse último caso, a realidade social é considerada a incontornável existência de vencedores e vencidos, decorrência inevitável da diferença natural entre as pessoas.

A essas imagens, assim sumariamente delineadas, subjazem diferentes visões de mundo, de sociedade e do próprio ser humano. Delas decorrem também distintas posturas com relação à formação das pessoas na sua relação com o mundo e a sociedade. O homem desde seus primórdios luta pelo domínio na esperança de livrar-se do medo e tornar-se senhor. Ameaçado pelos poderes da natureza e sendo inferior à maioria dos animais, sua única estratégia é o conhecimento racional. "Do medo”, dizem Adorno e Horkheimer (1985, p. 29), “o homem presume estar livre quando não há mais nada de desconhecido” . Essa convicção originária tornou-se sua estratégia de sobrevivência e de poder.

A longa história do esclarecimento encontrou seu momento decisivo na modernidade quando a ciência começou a decifrar os segredos da natureza e colocá-los a serviço do homem por meio da técnica. Cada vez menos importava à ciência a conquista da verdade, mas a operação, o procedimento eficaz. "O que não se submete ao critério da calculabilidade e da utilidade torna-se suspeito para o esclarecimento" (ADORNO; HORKHEIMER, 1985, p. 20, 211). Calculabilidade e utilidade transformaram-se então no padrão de ordenamento das relações entre homem e natureza e dos homens entre si. 
Na soma, o homem se orgulha dos avanços científico-tecnológicos que rompem as fronteiras da imaginação, mas ao mesmo tempo se envergonha da aviltante barbárie em que vive grande parte da humanidade. Degradado de motorneiro a passageiro, de condutor a conduzido, não compete mais ao homem determinar os rumos da história, mas ser levado por forças estranhas que ele mesmo produziu e agora fogem ao seu controle. A união entre conhecimento e poder, como dizem os mesmos filósofos, transformou-se na graça e na desgraça do homem, reconduzindo-o à dominação da qual sempre quis livrar-se.

Essas considerações teóricas nos ajudam a entender a natureza da educação contemporânea que, em grande medida, assumiu essa passagem do ideal da verdade para a busca do conhecimento e da operação. A operation como se lê na Dialética do Esclarecimento torna-se a espinha dorsal e o objetivo maior da educação. As instituições educativas transformam-se em ambientes nos quais não existe senão o indivíduo racional disposto a adquirir e incorporar conhecimentos e habilidades com o fim de integrar-se e operar na sociedade sem se importar com os sentidos culturais, sociais e psicológicos.

Também a universidade incorpora, pelo menos em grande medida, esse modelo: preparar o indivíduo racional para o mundo (mercado) mediante o incremento da razão e competência técnica. Já não importa a dimensão política e social do processo formativo. Na formulação de Adorno e Horkheimer (1985, p. 42), “[...] a exclusão do pensamento da lógica ratifica na sala de aula a coisificação do homem na fábrica e no escritório". Assim, "o eu integralmente capturado pela civilização se reduz a um elemento dessa inumanidade, à qual a civilização desde o início procurou escapar” . O conhecimento objetivo, matematizado, mantém o pensamento preso ao imediatamente dado, alienando os homens dos objetos dominados e coisificando o seu próprio espírito.

Quando a indústria invade a cultura, a vida e o pensamento, restringe-se a função do sujeito e inibe-se sua capacidade de ler e de interpretar a realidade. Os meios de comunicação se encarregam de ajustar os sentidos dos humanos ao diapasão sistêmico, de modo que a sua criatividade e imaginação não escapam mais aos poderosos tentáculos da maquinaria econômica. A indústria cultural, porta-voz da ideologia do sistema, confere naturalidade a todas as manifestações da ciência, da tecnologia e da indústria. Pelo idioma tecnicamente condicionado, familiar e íntimo do real, ela domestica o sujeito que perde sua capacidade de distanciamento crítico e de resistência. Não só se desarmam as tensões inerentes ao sistema, mas se glamouriza e enaltece pela banalização e repetição cínica o que não se pode mudar. Dessa forma, 
[...] a razão tecnológica triunfa sobre a verdade. Pela mediação da sociedade total, que engloba todas as relações e emoções, os homens se reconvertem exatamente naquilo contra o que se voltara a lei evolutiva da sociedade, o princípio do eu: meros seres genéricos, iguais uns aos outros pelo isolamento na coletividade governada pela força (ADORNO; HORKHEIMER, 1985, p. 47).

A universidade integrando-se e adaptando-se plenamente ao processo de transformação do mundo, incluindo aí a transformação do humano em indústria, nega o pensamento porquanto o reduz a mero espelho da realidade. Ao invés de voltar às raízes da modernidade para interrogar a respeito das razões dos erros que fizeram do projeto de tantas promessas e esperanças a história de uma nova barbárie, a universidade continua fiel à ilusão de que ciência e tecnologia resultarão numa sociedade mais justa e feliz. É uma espécie de faz de conta que insiste em desconsiderar a real história da razão moderna que o sofrimento, fome, guerras, holocaustos e destruição não permitem esquecer. Ao contrário do que imaginavam Kant e os idealistas no início da modernidade, tais eventos mostram que a própria razão não está isenta da barbárie (MATTÉI, 2002). De outra parte, o ser humano não tem outro meio de humanizar-se senão a razão. E é porque a razão não está isenta da barbárie que ela precisa de vigilância crítica para que não conduza a humanidade ao abismo. E é precisamente essa a maior carência da universidade.

Até mesmo o conjunto da linguagem acadêmica é uma linguagem funcional estreitamente ligada à racionalidade instrumental, tão enfaticamente criticada por Adorno. Os conceitos e palavras, ao invés de servirem ao esclarecimento, colocam-se a serviço do conhecimento objetivo e útil, sem espaço para seus sentidos e significados humanos. A divisão entre ciências e humanidades e o desprezo dessas últimas é a manifestação clara disso que a hegemonia da razão instrumental esconde. Na ciência, a palavra se transforma em signo, deixando de ser palavra propriamente dita enquanto expressão da subjetividade. Signo e palavra tornam-se realidades irreconciliáveis postadas uma ao lado da ordem, do estabelecido, da objetividade e do poder, e a outra ao lado do incomensurável. A divisão entre conceito e signo tende à destruição da verdade humana que a filosofia tenta em vão salvar. Tudo está decidido de antemão através da identificação antecipada do mundo totalmente matematizado com a verdade, a cujo serviço se coloca o pensamento como instrumento. Abandona-se assim toda a pretensão do conhecimento de romper a superfície do imediatamente dado para descobrir os sentidos sociais, históricos e humanos. 
Esse é o ambiente no qual se estrutura o ensino e a formação dos jovens universitários. São as expectativas do desenvolvimento econômico e do mercado de trabalho a referência primordial para a estruturação das carreiras, do currículo, das disciplinas e se organizam as preferências dos alunos. Traduz-se na prática o temor que Adorno e Horkheimer (1985, p. 38) pressagiavam na década de quarenta do século passado: a educação instrumental. "A equação do espírito e do mundo acaba por se resolver, mas apenas com a mútua redução dos dois lados. Na redução do pensamento a uma aparelhagem matemática está implícita a ratificação do mundo como sua própria medida". A afirmação da realidade social torna-se o modelo da formação do espírito. Desse modo, as instituições de ensino entre as quais se encontra a universidade transformam-se em agências de inserção das pessoas no processo de autoconservação do sistema formatando-os no corpo e na alma segundo a aparelhagem técnica a ponto de a razão transformar-se "[...] num mero adminículo da aparelhagem econômica". (ADORNO; HORKHEIMER, 1985, p. 40-42). Resta esperar que não se realize o presságio inscrito na dialética do esclarecimento: "[...] o inimigo que se combate é o inimigo que já está derrotado, o sujeito pensante” (ADORNO; HORKHEIMER, 1985, p. 140). A universidade pode contribuir para que isso não ocorra.

\section{A formação do sujeito cidadão}

Mesmo plenamente justificadas, as preocupações de Adorno com relação ao sujeito não devem levar-nos ao pessimismo com relação ao fim do sujeito nem levar-nos a pisar na armadilha objetivista do desprezo da subjetividade. Ao mesmo tempo em que autores estruturalistas, como Niklas Luhmann, não veem mais possibilidades de reação do sujeito e descartam as chances de um sujeito capaz de julgar e decidir autônoma e racionalmente sobre suas atitudes e comportamentos (LUHMANN, 1972, p. 378) e autores pós-modernos, como Gilles Lipovestky, pregam o relativismo de gostos, comportamentos e valores (LIPOVESTKY, 1989, p. 39). Há também outros pensadores, como o mencionado Komi Babha, que confiam nas possibilidades de elaboração de estratégias de subjetivação - singular ou coletiva - que podem ser negociados nos interstícios da emergente cultura (BABHA, 2007, p. 20).

No entanto, para que a esperança de Babha não se transforme em devaneio, é preciso permanecer com os pés no chão, pois nunca na história da humanidade o tecno-sistema teve tantos recursos e mecanismos para impor-se e influenciar as pessoas na sua subjetividade. Veja-se a consagrada argumentação de Adorno 
e Horkheimer a respeito dos efeitos massacrantes da indústria cultural sobre o sujeito. As estatísticas nos mostram quanto tempo os jovens passam cotidianamente expostos aos meios de comunicação, ouvindo discursos e vendo imagens símbolos do sistema. Subestimar os efeitos dessa realidade é como vendar os olhos ante o perigo eminente. Além disso, como desejo mostrar, a educação formal vinculada ao modelo social dedica-se desde os primeiros até os últimos anos à integração epistêmica e ética dos jovens na sociedade.

Mesmo assim, creio ainda haver tempo para reverter essa tendência e recuperar a vertente moderna da subjetividade hoje obnubilada pelo objetivismo da ciência \& tecnologia. Se bem é verdade que o indivíduo concebido como mônada isolada e autocentrada transformou-se no elemento central do liberalismo burguês que, segundo Marcuse (1967, p. 149), “[...] vê a sociedade como um todo que progride através da interação automática de interesses divergentes num mercado livre”, há também pensadores que, a exemplo de Marx, Gramsci, Adorno e tantos não cansam de repetir a pergunta se a humanidade do homem realmente deveria restringir-se à sua individualidade. Coloca-se assim o tema da relação indivíduo/sociedade não só como foco de exacerbados debates teóricos, mas também, como princípio estruturante de modelos socioeconômicos diferentes e opostos.

Analisado por muitos autores (HORKHEIMER (1976), MARCUSE (1973), ADAM SCHAFF (1967)) essa relação indivíduo/sociedade ressurge agora num momento histórico em que tanto o projeto socialista sem indivíduo quanto o indivíduo sem projeto social se veem ameaçados pelo enorme sorvedouro dos poderes econômicos. "Desde o dia do seu nascimento", confirma Horkheimer (1976, p. 152), “[...] o indivíduo é levado a sentir que só existe um meio de progredir nesse mundo: desistir de sua auto-realização suprema" [...] sacrificando "[...] suas potencialidades em proveito da capacidade de adaptar-se e conquistar influência em tais organizações".

Assumindo a ideia da proeminência irresistível do real que impõe como condição de sobrevivência a mimética adaptação das pessoas ao real, todo o processo de socialização e de educação do indivíduo passa a estruturar-se em torno desse requisito aparentemente inescusável da sociedade contemporânea. Em todos os seus níveis, como vimos acima, a educação se organiza e desenvolve estratégias com o objetivo de adaptar e integrar da maneira mais eficiente possível os indivíduos no contexto social. O indivíduo, assim plasmado no seu modo de pensar, valorar e sentir cuida de si mesmo não em função de sua autonomia, de sua capacidade de pensar e refletir, mas para otimizar sua acomodação à racionalidade autoperformática do sistema. Integrado, o sujeito deixa de ser ele mesmo não apenas enquanto ser individual autônomo, mas também, como ser político. Horkheimer (1976, p. 146) escreve que 
[...] a individualidade é prejudicada quando cada homem decide cuidar de si mesmo. À medida que o homem comum se retira da participação nos assuntos políticos, a sociedade tende a regredir à lei da selva, que esmaga todos os vestígios da individualidade!

Dessa ameaça só é possível proteger-se pela resistência consciente que está nas possibilidades do sujeito livre. Não sendo um dom natural, essa capacidade de resistir à avalanche de assédios sistêmicos depende de um processo de educação crítica, de formação (Bildung) da estrutura subjetiva do indivíduo.

No entanto, quando observamos o recorte da educação superior, vemos, conforme argumentei anteriormente, que o foco das atividades de ensino não é a formação de cidadãos críticos e reflexivos capazes de contribuir para a construção de uma a sociedade ética e solidária, mas instruir e habilitar para o mercado de trabalho. Se perguntássemos aos jovens o que esperam de sua formação universitária ou, em outros termos, qual o sentido social que justifica sua integração social, teríamos como provável resposta que eles se integram por questões técnicas, monetárias ou de sobrevivência e não em função da cidadania, da ética ou da política.

Surpreendentemente, é esse sentido limitado que corriqueiramente se atribui ao conceito de educação cidadã com graves consequências, não só terminológicas, tanto para a teoria quanto para a prática pedagógicas porque normaliza e justifica ideologicamente um modelo de educação como aquilo que ele não é. Cidadania, na verdade, lembra o direito e capacidade de participar da cives, ou seja, da sociedade política. Do ponto de vista da educação, significa a formação do sujeito autônomo que, embora participante ativo da vida social e econômica, sabe preservar a distância e a capacidade de julgar a partir de critérios referenciados no seu sentido humano.

Na contramão dessa perspectiva, a universidade insiste em transformar os seus alunos em recursos humanos úteis ao sistema econômico. Quanto mais rigidamente for atendida essa premissa, tanto melhor terá sido a educação aos olhos do sistema. Poucos são os espaços onde os jovens podem tomar a si mesmos como finalidade de sua educação, ou seja, não lhes é concedido o direito de serem seus próprios autores, sujeitos de sua própria existência, capazes de resistir a tudo aquilo que torna suas vidas incoerentes e sem sentido.

Não se nega que a universidade deva preparar seus estudantes para o mundo no qual devem atuar de forma consciente e responsável. Como diz Becker no seu debate com Adorno em Educação e emancipação, 
[...] evidentemente a aptidão para se orientar no mundo é impensável sem adaptações. Mas ao mesmo tempo impõe-se equipar o indivíduo de um modo tal que mantenha suas qualidades pessoais. A adaptação não deve conduzir à perda da individualidade em um conformismo unificador (BECKER, 1995, p. 144).

A sugestão de Becker para evitar o conformismo é ao mesmo tempo simples e rica: "A única possibilidade que existe é tornar tudo isso consciente na educação [...]” (BECKER, 1995, p. 154)

A universidade precisa reconhecer seus alunos como sujeitos, torná-los conscientes e ensiná-los a lidar com o pensamento que tem por objetivo a verdade e não apenas treiná-los para operar eficazmente o conhecimento e a tecnologia. À ciência agrega-se o conceito de utilidade operacional que confere domínio e poder ao ser humano, mas elimina o incomensurável, ou seja, aquilo que não pode ser medido nem calculado. Como na indústria os produtos, na sociedade os indivíduos se tornam fungíveis, meros exemplares substituíveis e descartáveis ao sabor dos interesses circunstanciais do sistema se eles não se valorizarem como seres humanos. O eu desintegrado de si e integrado na ordem social submete o mundo e a si mesmo ao "[...] identificar a verdade em geral com o pensamento ordenador” (ADORNO; HORKHEIMER, 1985, p. 28). Por isso, os estudantes precisam aprender na universidade que a verdade não se identifica com o real; precisam aprender a serem seres sociais sem se tornarem reféns da lógica sistêmica; precisam desenvolver consciência crítica para reconhecer e problematizar os sentidos unívocos do real; precisam, enfim, saber formular juízos independentes e autônomos sobre a realidade social, política e econômica na qual deverão inserir-se e realizar-se como seres humanos.

A resposta para a questão levantada por Becker a respeito do duplo sentido da formação das pessoas para si e para a sociedade nos é fornecida por Adorno que chama a atenção para a sempre tensa, paradoxal e dialética relação que existe entre o sujeito e a sociedade. Não é possível, diz o filósofo, trabalhar com a ideia de uma espécie de harmonia e nem de dicotomia entre "[...] o que funciona socialmente e o homem formado em si mesmo". Trata-se, na verdade, de uma relação tensa em que nenhum dos polos pode ser reduzido ao outro, uma relação que jamais alcança harmonia. Ao mesmo tempo trata-se de uma relação essencial tanto ao indivíduo quanto à sociedade que se destroem ao serem reduzidos um ao outro. A sociedade sem indivíduos conscientes, autônomos, e resistentes transforma-se num sistema do medo e da colonização; de outra parte, o indivíduo isolado transforma-se em mônada carente de sentido humano. 
Trata-se, portanto, de uma relação dialética, historicamente dinâmica e constituinte, por definição, do indivíduo e da sociedade. Imprescindível é tornar consciente essa relação de permanente aproximação e distanciamento ao invés de dissimulá-la sob a ideologia do ideal de uma falsa harmonia não só inatingível, mas absolutamente indesejável de ser alcançada. O domínio de um ou de outro lado resultará sempre em barbárie. Mattéi (2002, p. 19) lembra que a barbárie é "[...] uma atitude consubstancial a todo estado de civilização" que só pode ser evitado pela educação. Por isso, Adorno define a desbarbarização da relação sociedade/indivíduo como a tarefa central da educação. A estratégia para alcançar esse objetivo é a geração da consciência crítica do sentido da existência, do pensar que não se identifica com a produção e acumulação de conhecimentos. Educação cidadã é estimular a abertura ao sentido ético da existência em sociedade.

\section{Conclusão}

O tema da pertinência social foi abordado a partir de três aproximações conceituais: a pertinência social da universidade, a educação instrumental e a formação do sujeito cidadão. Em cada um desses momentos procurei destacar os sentidos ambivalentes inerentes ao uso comum dos conceitos mencionados e apontar em que termos se dimensiona a relação entre universidade e sociedade.

No primeiro momento, tentei explicitar que o sentido positivo do conceito de pertinência encontra-se condicionado pelo modelo de sociedade que a universidade visa estimular com suas atividades de pesquisa, ensino e extensão. Desejável é o estreitamento entre a universidade e a sociedade quando essa aproximação objetiva favorecer a construção de uma sociedade mais digna, justa e democrática. Nesse sentido, não é indiferente qual o tipo de contribuição em termos de conhecimento, ensino ou extensão a universidade aporta à sociedade. Em outras palavras, ao termo pertinência social é inerente uma dimensão ética que não pode deixar de ser considerada.

No segundo momento, me propus destacar o ensino como importante dimensão da pertinência social da universidade, o que parece não ser muito comum. Seguindo o mesmo procedimento que perpassa todo o texto, tratei de assinalar algumas dicotomias inerentes ao ensino, a partir da explicitação do termo educação instrumental. Como no item anterior, foi preciso perguntar também aqui qual o sentido que subjaz à prática docente. Busquei tornar plausível que o sentido pleno da pertinência social da universidade não se cumpre com a mera instrumentalização ou enquadramento dos estudantes sistema social hegemônico. 
Por último e na sequência do passo anterior, trouxe ao debate o termo educação para a cidadania, bastante usado quando o tema é pertinência social da universidade, como se depreende do teor de muitos documentos e discursos oficiais. Também aqui nos defrontamos com diferentes e dicotômicas acepções do conceito educação cidadã que quando agregadas à pertinência social the conferem sentidos muito distintos. De modo geral, aplica-se aqui o conceito de educação instrumental anteriormente discutido entendendo formação cidadã como acomodação do indivíduo à realidade social. Contrariamente a isso, defendo que a tarefa central da educação corresponde tanto à habilitação do indivíduo para a atuação no contexto social quanto ao desenvolvimento da capacidade reflexivo crítica do próprio sujeito.

\section{REFERÊNCIAS}

ADORNO, Theodor. Educação e emancipação. Tradução de: MAAR, Wolfgang Leo. São Paulo: Paz e Terra, 1995.

ADORNO; HORKHEIMER. Dialética do esclarecimento. Tradução de: ALMEIDA, Guido Antonio de. Rio de Janeiro: Jorger Zahar, 1985.

BHABHA, Homi K. O local da cultura. Tradução de: ÁVILA, Myriam; REIS, Eliana L. de L.; GONÇALVEZ, Glaucia R. Belo Horizonte: Editora UFMG, 2007.

HORKHEIMER, Max. Eclipse da razão. Tradução de: LEITE, Sebastião Uchoa. Rio de Janeiro: Editorial Labor do Brasil, 1976.

HORKHEIMER, Max. Autoridade e família. In: HORKHEIMER, Max. Teoria Crítica I. Tradução de: COHN, Hilde. São Paulo: Edusp, 1990.

LIPOVETSKY, Gilles. A era do vazio: ensaio sobre o individualismo contemporâneo. Tradução de: PEREIRA, Miguel Serra; FARIA, Ana Luisa. Lisboa: Relógio D’água, 1989.

LUHMANN, Niklas; HABERMAS, Jürgen. Theorie der Gesellschaft oder Sozialtechnologie. Frankfurt: Suhrkamp Verlag, 1972.

MARCUSE, Herbert. Repressive Toleranz. In: WOLF, Robert Paul, et al. Kritik der reinen Toleranz. Frankfurt am Main: Suhrkamp Verlag, 1967. 
MARCUSE, Herbert. A ideologia da sociedade industrial: o homem unidimensional. Tradução de: REBUÁ, Giasone. Rio de Janeiro: Zahar Editor, 1973.

MARCUSE, Herbert. Cultura e sociedade. Tradução de: MAAR, Wolfgang Leo; LOUREIRO, Isabel Maria; OLIVEIRA, Robespierre de. São Paulo: Paz e Terra, 1997.

MATTÉI, Jean-François. A barbárie interior. Tradução de: LOUREIRO, Isabel Maria. São Paulo: Editora Unesp, 2002.

SCHAFF, Adam. O marxismo e o indivíduo. Tradução de: SILVA, Heidrun Mendes da. Rio de Janeiro: Edit. Civilização Brasileira, 1967.

TOURAINE, Alain. Um novo paradigma para compreender o mundo de hoje. Tradução de: TITTON, Gentil Avelino. Petrópolis: Editora Vozes, 2006.

WOLF, Robert Paul, et al. Kritik der reinen Toleranz. Frankfurt am Main: Suhrkamp Verlag, 1967.

Texto recebido em 15 de janeiro de 2010 .

Texto aprovado em 20 de fevereiro de 2010. 